\title{
Field evaluation of a simple infiltration test and its relationship with bulk density and soil organic carbon in California rangelands
}

\author{
E.L. Porzig, N.E. Seavy, B.E. Owens, and T. Gardali
}

\begin{abstract}
Water infiltration is commonly recommended as an indicator of soil dynamic properties and water cycling on rangelands. We investigated the utility of a two-trial single-ring infiltration test by evaluating the relationship between the first and second trial, the spatial variation in infiltration rates within and between sampling locations, and the relationship between water infiltration and bulk density and soil organic carbon (SOC) in the context of texture and water content. We measured water infiltration rates at 156 sites in 14 counties in California. We found a strong correlation between first and second infiltration trials. In pairwise correlations, both first and second trials were significantly correlated with SOC and bulk density. However, we did not find a significant relationship between water infiltration and either initial water content or soil texture. Model comparison revealed that in the context of soil texture, infiltration can serve as an indicator of bulk density and SOC; shorter water infiltration time (i.e., faster rate) is associated with decreased bulk density and increased SOC. Our results suggest that a single-ring infiltration test can be a useful, but imprecise, indicator of soil dynamic properties such as SOC and bulk density.
\end{abstract}

Key words: ecological indicators — infiltration-monitoring — rangeland

Simple indicators of ecological function are needed to help land managers monitor rangeland condition and changes due to management (Pyke et al. 2002; West 2003). While there are many definitions of indicators (Heink and Kowarik 2010), we propose that in the context of rangeland condition, the indicators that are most meaningful and needed are descriptive ecological indicators that help managers understand the state of rangeland ecosystems and the response to management. Useful rangeland indicators will be relatively easy to quantify, and signal patterns in a broader phenomenon of interest. As such, they can be expected to correlate with several other metrics, and causal mechanisms linking metrics can be interrelated (Hammond 1995; Niemeijer 2002).

Monitoring of such indicators can assist managers challenged by a rapidly changing climate and uncertainty about impacts of management practices on environmental and agricultural outcomes (Shaw et al. 2011; Polley et al. 2013). Indicators that relate to the water cycle and soil function are especially important because of the fundamental role that water availability plays in biological activity and productivity, which is critical when rangeland management goals are focused on conservation, production, or both (Lal 1998; Ludwig et al. 2004). Furthermore, indicators relating to water and soil are relevant to the goals of reducing soil loss to erosion and preparing for a potential shift to a drier climate (Polley et al. 2013).

Water infiltration-the movement of water into the soil-is a critical component of soil and ecological function (Lowery et al. 1996). Water infiltration is one determinant of how much water is available for plant growth and ground water recharge, as well as runoff potential and erosion risk (Franzluebbers 2002). Water infiltration is determined by both properties that are insensitive to management (e.g., texture [Lowery et al. 1996]) and properties that can change in response to land use, such as compaction and the amount of soil organic matter (Franzluebbers 2002). While measurements such as bulk density and soil organic matter are recognized as good indicators of soil function, they require both a field and a lab component to the measurement. In contrast, water infiltration is an entirely field-based measurement; it is potentially more intuitive and thus may be more accessible to managers than other indicators. If a simple water infiltration test can indicate other important aspects of ecological function, its utility to land mangers is increased.

There are numerous ways to measure the process of water infiltration and associated parameters that vary dramatically in their complexity. Many of these are designed to eliminate or control for the effect of soil water content. Methods include rainfall simulators (Wierda and Veen 1992), Guelph permeameters (Reynolds and Elrick 1985), disk tension infiltrometers (Haverkamp et al. 1994), borehole tests (Stephens et al. 1987), and ring infiltrometers (Lowery et al. 1996). Among these, the ring infiltrometer is by far the least complicated. As a result, the ring infiltrometer is often recommended as a way to evaluate water infiltration in rangeland soils (Lowery et al. 1996; USDA NRCS 1999).

In the USDA Natural Resources Conservation Service (NRCS) Soil Quality Test Kit (USDA NRCS 1999), water infiltration is measured using a single-ring infiltration test with two trials. By wetting the soil with back-to-back trials, this simple test is designed to control for soil water content by bringing soil moisture to field capacity with the first trial and using the second trial as a measure of saturated hydraulic conductivity (Lowery et al. 1996). The materials to conduct the test can be purchased and assembled for less than US $\$ 10$. However, the results are often highly variable over small spatial scales even on the same soil type, and more information about their interpretation is needed at regional scales (Sharma et al. 1980; Buttle and House 1997).

Our goal was to better understand the utility of a simple water infiltration test as an indicator

Elizabeth L. Porzig is a senior ecologist at Point Blue Conservation Science in Petaluma, California. Nathaniel E. Seavy is a research director at Point Blue Conservation Science in Petaluma, California. Breanna E. Owens is the coordinator of the Rangeland Watershed Initiative at Point Blue Conservation Science in Petaluma, California. Thomas Gardali is the director of the Pacific Coast and Central Valley Group at Point Blue Conservation Science in Petaluma, California. 
of rangeland ecosystems. Thus, we investigated the relationship between a two-trial single-ring water infiltration test and other soil properties across soil types in California rangelands. We had the following objectives:

1. Determine the relationship between first and second trials in the two-trial test.

2. Investigate the magnitude of spatial variation in water infiltration rates within and across sampling locations.

3. Quantify the correlation between infiltration rates, soil organic carbon (SOC), bulk density, soil texture, and soil water content across sampling locations.

4. Evaluate the value of infiltration rates as indicators of bulk density and soil C.

\section{Materials and Methods}

Study System. The Rangeland Monitoring Network measures soil dynamic properties as part of a suite of indicators of ecological function on rangelands across California (Porzig et al. 2016). These measurements are collected primarily on private land at properties where landowners are engaged in efforts to improve rangeland health, often with assistance through programs offered by the USDA NRCS. Participating properties are not identified as part of a preassigned study design, but instead are determined by landowners and land managers who volunteer to participate.

From the fall of 2014 through the spring of 2016, we measured water infiltration, SOC, bulk density, soil water content, and soil texture at 39 properties in 14 counties in California as part of the Rangeland Monitoring Network (figure 1).

Sampling Design. Within a property, we identified sampling locations following a three step process. First, using the Military Grid Reference System, we identified a sampling frame of $250 \mathrm{~m}^{2}\left(299 \mathrm{yd}^{2}\right)$ points. We then used the Generalized Random Tesselation Stratification algorithm to select a spatially balanced random subset of candidate locations within this grid using the "spsurvey" library in R (R Core Team 2016; Kincaid and Olsen 2013). We sampled soils at a subset of these locations that we selected by stratifying across soil type and vegetation type (Porzig et al. 2016). Locations were associated with grasslands, oak savanna, oak woodland, coastal prairie, and coastal scrub.

The number of sampling locations per property varied from one to eight, and we had a total of 156 locations across these properties.

\section{Figure 1}

Map of California showing the study area counties shaded and sample sizes within each county.

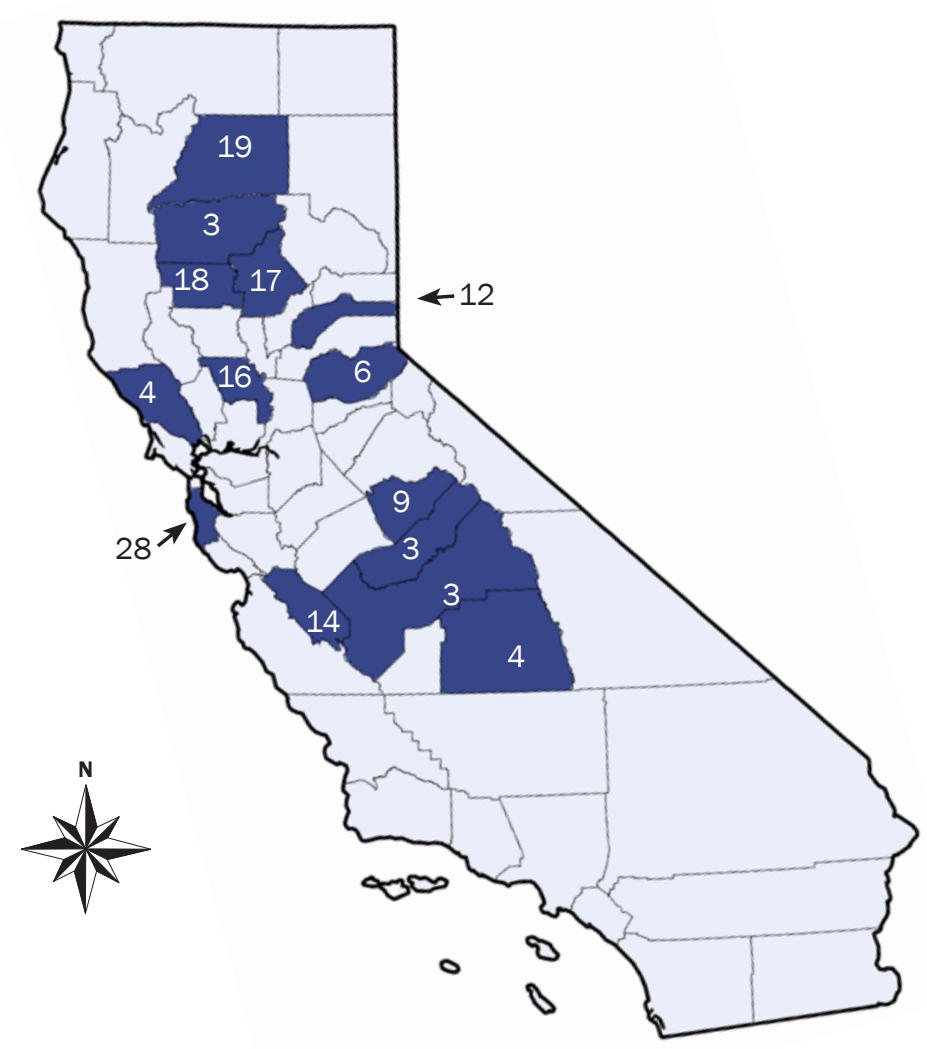

However, the sample size varied slightly from analysis to analysis, as reported below.

Data Collection. At each sampling location, we randomly identified five subsample sites within $50 \mathrm{~m}(164 \mathrm{ft})$ of the location center. At these subsample sites, we measured water infiltration, bulk density, and water content. Additionally, we pooled soil from the five subsample sites from which we took a single measurement of soil $\mathrm{C}$ and soil texture for the location. For most analyses, we averaged across subsample sites to generate a single value of water infiltration, bulk density, and water content for a location.

Water Infiltration Test. We measured water infiltration rates following the protocol in the USDA NRCS Soil Quality Test Kit (USDA NRCS 1999). We inserted a $15.2 \mathrm{~cm}$ (6 in) diameter polyvinyl chloride (PVC) ring with a beveled leading edge into the ground to $5 \mathrm{~cm}$ ( 2 in) depth. We placed a plastic sheet in the ring and poured in 450 $\mathrm{mL}(15.22 \mathrm{oz})$ of water, removed the sheet, and recorded the time it took for the water to enter the soil. Following the initial trial, we reinserted the plastic sheet, added another $450 \mathrm{~mL}$ of water, and again recorded the infiltration time. In instances where the first trial took longer than 50 minutes, we did not conduct the second trial. If the second trial lasted more than 45 minutes, we stopped the timer, measured the depth of the remaining water, and extrapolated the amount of time it would have taken the water to enter the soil assuming the rate measured over the 45 minutes was applied to the remaining volume of water. We recognize that this rate is often assumed to be asymptotic; however, in this case we felt a linear relationship is a close approximation. Because our objectives included evaluating the relationship between the first and second trial and comparing the explanatory power of both trials, we only analyzed data from locations where both trials were measured; data were not included when the second trial was not performed.

Bulk Density. We measured bulk density of the surface soil by inserting a ring 5.2 $\mathrm{cm}$ (2 in) in diameter and $7.5 \mathrm{~cm}$ (3 in) tall into the ground and removing the ring with 
soil contents. The contents of the ring were sealed in plastic bags; shortly after field sampling (typically within 24 hours), the samples were weighed to the nearest $0.1 \mathrm{~g}(0.035 \mathrm{oz})$. In the lab, we removed rocks by sifting samples through a $2 \mathrm{~mm}$ (0.08 in) mesh sieve. We weighed rocks and determined volume by displacing water in a graduated cylinder. Samples were then dried in an oven at $100^{\circ} \mathrm{C}\left(212^{\circ} \mathrm{F}\right)$ for 24 hours. We weighed the samples again and the following calculation was used to estimate bulk density $\left(\mathrm{g} \mathrm{cm}^{-3}\right)$ :

Bulk density = oven dry weight of soil $\div$ (volume of bulk density ring - volume of rocks).

Because we sampled in a diversity of soils with different coarse fractions, we chose to calculate bulk density on the fine fraction $(<2 \mathrm{~mm}[<0.08 \mathrm{in}])$ as this is often a preferred method in these circumstances (Grossman and Reinsch 2002).

Water Content. We calculated volumetric water content using the following equation as described in Jarrell et al. (1999):

Volumentric water content $=[($ moist soil dry soil $) \div$ dry soil $] \times$ bulk density.

Organic Carbon. We sampled organic C to $40 \mathrm{~cm}$ (15.7 in) depth, separating the 0 to $10 \mathrm{~cm}$ (0 to 4 in) depth from the 10 to $40 \mathrm{~cm}$ (4 to 15.7 in) depth, using either a step probe or sampling soil from the clean face of a pit. We combined the five subsamples taken around the center of each sampling location. Inorganic carbonates were removed with an acid pretreatment, and organic C was measured by dry combustion using an Elemental Analyzer at the University of Idaho Soil Analytic Lab.

Soil Texture. For particle size analysis, we again combined the five subsamples taken around the center of each sampling location. Particle size analysis was conducted at the University of Idaho Soil Analytic Lab. Soil texture varied among sampling location, particularly along the sand and clay axes (figure 2). We performed principle components analysis on the percentage sand, silt, and clay at each sampling location to reduce the dimensionality of soil texture to a single variable. The first principle component explained $72 \%$ of the variation in texture. This variable is inversely related to percentage sand, with higher values of the principle coordinate associated with more small particles (clay and silt), and lower values associated with more sand.

Relationship between Successive Water Infiltration Trials. To evaluate relationship between the first and second trial, we treated each of the five subsamples as a replicate and then evaluated the correlation between the two trials. In order to allow for the possibility of a nonlinear relationship between the two trials, we quantified the linear relationship between the raw measurements, the linear relationship between the $\log$ of the measurements, and the relationship in which the second measurement is a nonlinear function of the first, fitted with a Generalized Additive Model (GAM) (Guissan and Thuiler 2005; Zuur et al. 2010).

Comparing Spatial Variation within Locations to Spatial Variation across Locations. To describe and evaluate the spatial variation in water infiltration, we plotted on a $\log$ scale the infiltration rate for each subsample with the mean of those subsamples that described water infiltration for the location. This graph allowed us to visually compare the variability in infiltration rates within a location to variation across locations.

Correlation between Water Infiltration and Inherent and Dynamic Soil Properties. To quantify the relationship between water infiltration and soil properties, we used Pearson's correlation coefficients. The purpose of this analysis was to explore the raw correlations between the different characteristics to identify the strongest relationships. For the first and second infiltration trial, we used log-transformed values, but we used untransformed measurements for organic C, volumetric water content, bulk density, and texture values, as these values met assumptions for normally distributed values. Sample size for this analysis was 134 ; locations missing one or more variables were removed.

Water Infiltration as Indicator for Dynamic Soil Properties. To evaluate the efficacy of water infiltration as a predictor of bulk density and soil $\mathrm{C}$, we fitted a suite of models that used water infiltration and other variables (see below) to predict these soil dynamic properties. In order to accommodate the potential for nonlinear relationships between water infiltration and soil dynamic properties, we used a flexible GAM (Guissan and Thuiler 2005; Zuur et al. 2010). These models can accommodate a wide variety of relationships between predictor and response variables. For bulk density and soil $\mathrm{C}$ we compared five candidate models with water infiltration, texture, and water content as predictors both individually and in combinations (table 1). We selected the candidate set of models a priori to help us understand the degree to which water infiltration provides information about SOC and bulk density beyond what would be expected based on texture alone. For each model, we calculated Akaike's Information Criterion adjusted for small sample size (AICc) and the difference in AICc between each candidate model and the model with the lowest AICc value ( $\triangle \mathrm{AICc}$ ) to rank and select the best models (Burnham and Anderson 2002). While our sample size is substantial, we still use AICc as opposed to AIC because as sample size increases, AICc is equivalent to AIC (Burnham and Anderson 2002). We considered candidate models with $\triangle \mathrm{AICc} \leq 2$ to have substantial support and to be ecologically meaningful (Burnham and Anderson 2002). We were specifically interested in the degree with which models including water infiltration were better supported than those including only soil texture and water content. Finally, we fitted these models using both the first and second water infiltration trials and compared the results to evaluate (1) whether there was consistency in the best supported model between trials, and (2) which of the trials generated a model that explained more of the variation, indicated by a higher $R^{2}$. Sample size for this analysis was 134 ; locations missing one or more variables were removed. All analyses were performed in $\mathrm{R}$ version 3.2.4 ( $\mathrm{R}$ Core Team 2016).

\section{Results and Discussion}

A simple water infiltration test provides an accessible and affordable means for a land manger to assess the rate at which surface water enters the soil, as well as the amount of runoff and erosion risk. Our results indicate that water infiltration tests can also be a useful, though imprecise, indicator of other soil dynamic properties, specifically SOC and bulk density. This expands their utility in the soil monitoring toolbox.

Relationship between Successive Water Infiltration Trials. We evaluated the correlation between the first and second water infiltration trials at each subsample location using $R^{2}$ values generated from four separate models. The linear model and the additive model fit to the log-transformed infiltration times were comparable and higher than the 


\section{Figure 2}

Soil texture triangle. Points are texture classifications for each of the sample locations.

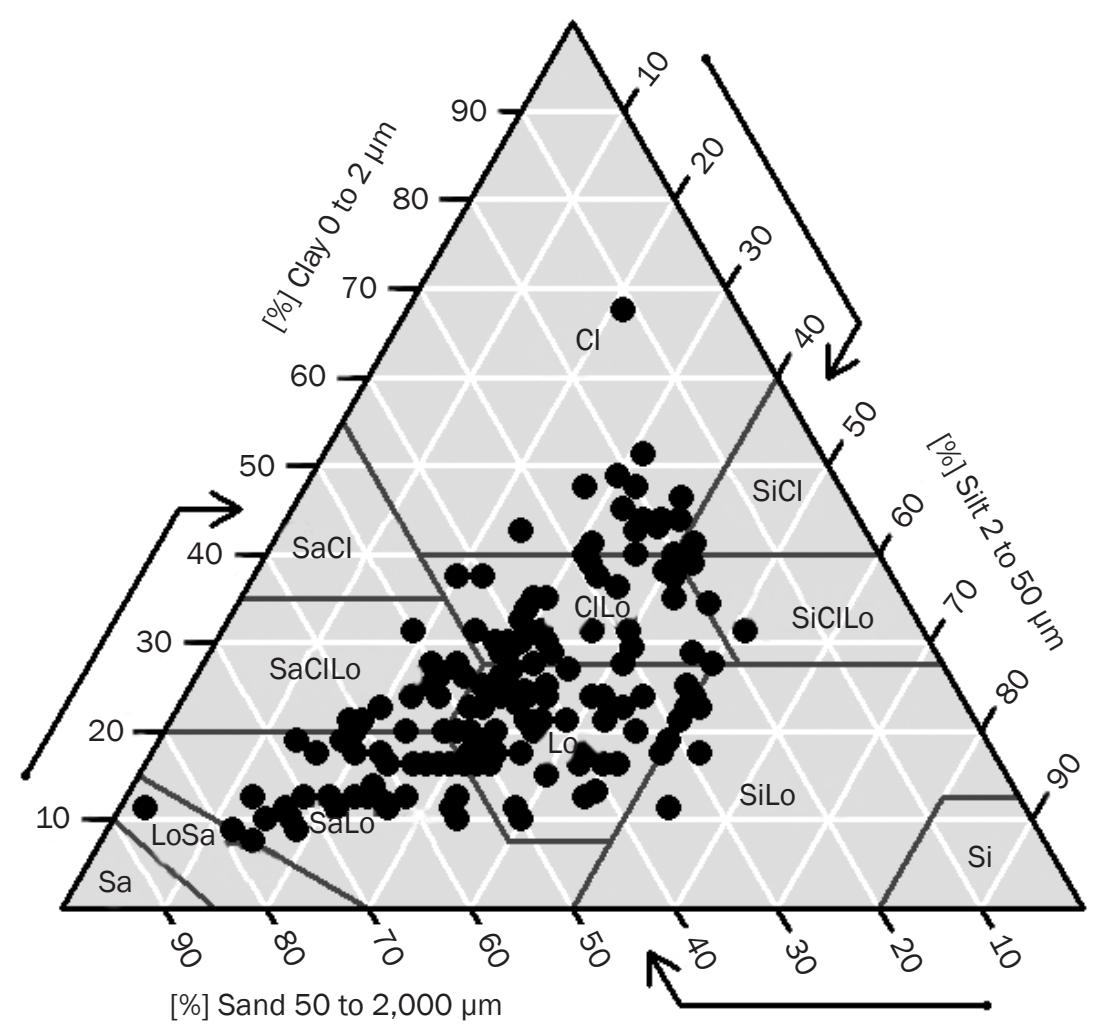

$R^{2}$ values of the linear and additive models fit to the untransformed values (table 2). On a log-scale, the first water infiltration measurement is strongly correlated $\left(R^{2}=0.81\right)$ with a second trial conducted immediately after the first. This suggests that the first and second trials contain much of the same information (figure 3).

Comparing Spatial Variation within Locations to Spatial Variation across Locations. Across the locations we measured, there is substantial variation in infiltration times, with mean times ranging from 0.033 minutes to 148 minutes. When we plotted the times of subsamples for a given mean (figure 4), we found that points that had rather large difference in the mean (e.g., $\sim 200 \%$ ) could still have substantial overlap in the subsample times.

The amount of variation in infiltration rates observed over a small spatial area (50 $\mathrm{m}[164 \mathrm{ft}]$ radius circle) suggests that using infiltration as an indicator is most appropriate when looking for large differences in soil properties. Our analyses demonstrated that two samples that differ by more than $500 \%$ (e.g., points with times of 0.1 and 0.5 minutes) could be easily distinguished by our protocol with a mean of five samples. However, smaller differences (e.g., of roughly $200 \%$ may not be as reliably interpreted because of the spatial heterogeneity of subsamples (figure 4). One option for addressing this would be to increase the number of subsamples within a location in order to increase the precision of the estimate.

Correlation between Water Infiltration and Inherent and Dynamic Soil Properties. Both the first and second trials were significantly negatively correlated with SOC (first trial $p=0.04$; second trial $p=0.04$ ) and significantly positively correlated with bulk density (first trial $p<0.01$; second trial $p<$ 0.01) (figure 5). These are consistent with the relationships that have been reported in numerous other studies (Huntington et al. 1989; Sakin 2012). The correlations between infiltration and water content or texture were not significant. This contrasts with previous studies demonstrating correlations between soil texture and water content (Jarvis and Messing 1995; Lowery et al. 1996; Reynolds et al. 2000). A possible explanation for this discrepancy may be that while we measured infiltration over a gradient in water content and texture, the variation was not wide enough to detect a significant correlation. While soil textures range from loamy sand to clay soils (figure 2), the majority of the distribution in clay content (from the first to the third quartiles) only varied from $18 \%$ to $34 \%$ clay. Similarly, although water content varied from $0.03 \mathrm{~mL} \mathrm{H}_{2} \mathrm{O} \mathrm{cm}{ }^{-3}\left(0.05 \mathrm{oz} \mathrm{H}_{2} \mathrm{O}\right.$ $\mathrm{in}^{-3}$ ) to $0.89 \mathrm{~mL} \mathrm{H}_{2} \mathrm{O} \mathrm{cm} \mathrm{cm}^{-3}\left(1.6 \mathrm{oz} \mathrm{H}_{2} \mathrm{O} \mathrm{in}^{-3}\right)$, the majority of the distribution (from the first to the third quartiles) varied by $0.12 \mathrm{~mL} \mathrm{H}_{2} \mathrm{O}$ $\mathrm{cm}^{-3}\left(0.22 \mathrm{oz} \mathrm{H}_{2} \mathrm{O} \mathrm{in}^{-3}\right)$. Furthermore, all sampling was conducted after the first rain of the season after the soil had already been wetted.

Water Infiltration as Indicators for Dynamic Soil Properties. While the pairwise correlations demonstrate consistent relationships among the variables, they may fail to detect more complex patterns. To further examine the relationship between water infiltration and the other soil dynamic properties, we compared competing models to identify the models that best predicted soil C and bulk density. For soil $\mathrm{C}$, we found that all top models (within $\triangle \mathrm{AIC} \leq 2$ ) included soil texture, most included water infiltration, and some include water content (table 1). The results were relatively consistent between the first and second infiltration trial; the deviance explained by the best model using the first trial $(9.65 \%)$ was only slightly less than the deviance explained by the best model using the second trial (11.3\%).

For bulk density, we found that all top models (within $\triangle \mathrm{AIC} \leq 2$ ) included soil texture and water infiltration, and some included water content. The results were relatively consistent between the first and second infiltration trial. The deviance explained using the top model of the first trial (19.6\%) was slightly greater than that explained by the top model using the second trial (14.3\%).

These results suggest that in the context of soil texture, water infiltration can serve as an indicator of SOC and bulk density (table 1). However, the limited deviance explained by each of the top models indicates that the explanatory power of even the best model is still relatively low. In the context of repeated sampling through time, water infiltration could prove to be informative because soil texture remains constant over time, thus changes in water infiltration may be indicative of changes in soil organic matter and bulk density. 


\section{Table 1}

Model comparison tables evaluating the relationship between the first and second infiltration trials and soil organic carbon (SOC) and bulk density.

\begin{tabular}{|c|c|c|c|c|c|c|}
\hline Influence & Response & Predictors & $\triangle \mathbf{A I C c}$ & \# Param. & Weight & $\begin{array}{l}\text { \% Dev. } \\
\text { Expl. }\end{array}$ \\
\hline \multicolumn{7}{|c|}{ Influence of the first trial and covariates on SOC } \\
\hline & $\mathrm{SOC}, 0$ to $10 \mathrm{~cm}$ depth & In(first trial) & 5.2 & 3.0 & 0.035 & 3.18 \\
\hline & $\mathrm{SOC}, 0$ to $10 \mathrm{~cm}$ depth & In $($ first trial $)+$ water content + texture & 2.1 & 5.9 & 0.163 & 9.67 \\
\hline & SOC, 0 to $10 \mathrm{~cm}$ depth & In(first trial) + texture & 0.0 & 4.9 & 0.472 & 9.65 \\
\hline & SOC, 0 to $10 \mathrm{~cm}$ depth & Texture & 1.3 & 3.8 & 0.246 & 7.09 \\
\hline & SOC, 0 to $10 \mathrm{~cm}$ depth & Water content + texture & 3.4 & 4.8 & 0.085 & 7.08 \\
\hline \multicolumn{7}{|c|}{ Influence of the second trial and covariates on SOC } \\
\hline & $\mathrm{SOC}, 0$ to $10 \mathrm{~cm}$ depth & In(second trial) & 6.6 & 4.0 & 0.019 & 3.98 \\
\hline & SOC, 0 to $10 \mathrm{~cm}$ depth & $\ln ($ second trial $)+$ water content + texture & 2.2 & 6.8 & 0.172 & 11.30 \\
\hline & SOC, 0 to $10 \mathrm{~cm}$ depth & $\ln ($ second trial) + texture & 0.0 & 5.8 & 0.510 & 11.30 \\
\hline & soc, 0 to $10 \mathrm{~cm}$ depth & Texture & 1.7 & 3.8 & 0.220 & 7.09 \\
\hline & SOC, 0 to $10 \mathrm{~cm}$ depth & Water content + texture & 3.8 & 4.7 & 0.076 & 7.08 \\
\hline \multicolumn{7}{|c|}{ Influence of the first trial and covariates on bulk density } \\
\hline & Bulk density & In(first trial) & 7.6 & 4.2 & 0.013 & 12.80 \\
\hline & Bulk density & In(first trial) + water content + texture & 0.6 & 6.4 & 0.410 & 20.50 \\
\hline & Bulk density & In(first trial) + texture & 0.0 & 5.7 & 0.570 & 19.60 \\
\hline & Bulk density & Texture & 12.2 & 3.0 & 0.001 & 8.01 \\
\hline & Bulk density & Water content + texture & 13.2 & 4.0 & 0.000 & 8.72 \\
\hline \multicolumn{7}{|c|}{ Influence of the second trial and covariates on bulk density } \\
\hline & Bulk density & In(second trial) & 8.6 & 3.2 & 0.007 & 6.60 \\
\hline & Bulk density & In(second trial) + water content + texture & 0.5 & 5.6 & 0.400 & 15.40 \\
\hline & Bulk density & In(second trial) + texture & 0.0 & 4.6 & 0.530 & 14.30 \\
\hline & Bulk density & Texture & 6.1 & 3.0 & 0.025 & 8.01 \\
\hline & Bulk density & Water content + texture & 7.2 & 4.0 & 0.015 & 8.72 \\
\hline
\end{tabular}

Notes: Top models (of $\triangle \mathrm{AICc} \leq 2$ ) are in bold font. $\triangle \mathrm{AICc}=$ the difference in AICc score between the listed model and the best model (i.e., the model with the lowest AICC score). \# Param. = the number of parameters used to estimate the model. Weight $=$ the relative likelihood of the listed model divided by the sum of the relative likelihood of all candidate models. \% Dev. Expl. = percentage deviance explained.

Another dimension to the ability of water infiltration to serve as an effective indicator is illustrated by the way it is received by practitioners. During sampling visits completed with managers, we observed that the infiltration test generated more interest and discussion than bulk density or SOC sample collection. This field test can provide the land manager a way of gathering an in situ estimation of saturated hydraulic conductivity and inspire hypothesis generation, potentially informing adaptive management in ways that metrics that require lab assays with associated delays in reporting cannot.

The Contribution of the Second Trial. The purpose of the first trial in the twotrial method is to bring the area within the infiltration ring to field capacity, thereby reducing sampling variability attributable to soil water content (Lowery et al. 1996; USDA NRCS 1999). While our infiltration tests were conducted in varying soil moisture conditions, they had all occurred after the first rain of the season, such that at least some

\section{Table 2}

Four models describing the relationship between the first and second infiltration trials and the $R^{2}$ value for each model.

\begin{tabular}{ll}
\hline Model & $\boldsymbol{R}^{2}$ \\
\hline Linear; first trial $\sim$ second trial & 0.63 \\
Linear; log(first trial) $\sim \log ($ second trial) & 0.81 \\
GAM; first trial $\sim$ second trial & 0.66 \\
GAM; log(first trial) $\sim \log ($ second trial) & 0.82 \\
\hline
\end{tabular}

Note: GAM = generalized additive model.

soil moisture was present. Our results suggest that there is relatively little information gained by performing the second trial. We found that the first and second water infiltration rates were strongly correlated, although the second trial was consistently longer than the first (table 2; figure 3). We also found that the second trial did not exhibit stronger pairwise correlations with bulk density or SOC (figure 5). Additionally, we found that models that used water infiltration to predict soil
C and bulk density were not substantially improved by using one trial over the other (table 1). Overall, our results suggest that in our system, the first water infiltration trial may be sufficient as an indicator of bulk density and SOC.

\section{Summary and Conclusions}

Single-ring infiltration tests are a relatively simple, affordable, and demonstrative way to evaluate how quickly water can enter the soil, 


\section{Figure 3}

Variation in the first infiltration trial compared to the second infiltration trial. $450 \mathrm{~mL}$ of water was applied over $180 \mathrm{~cm}^{2}$.

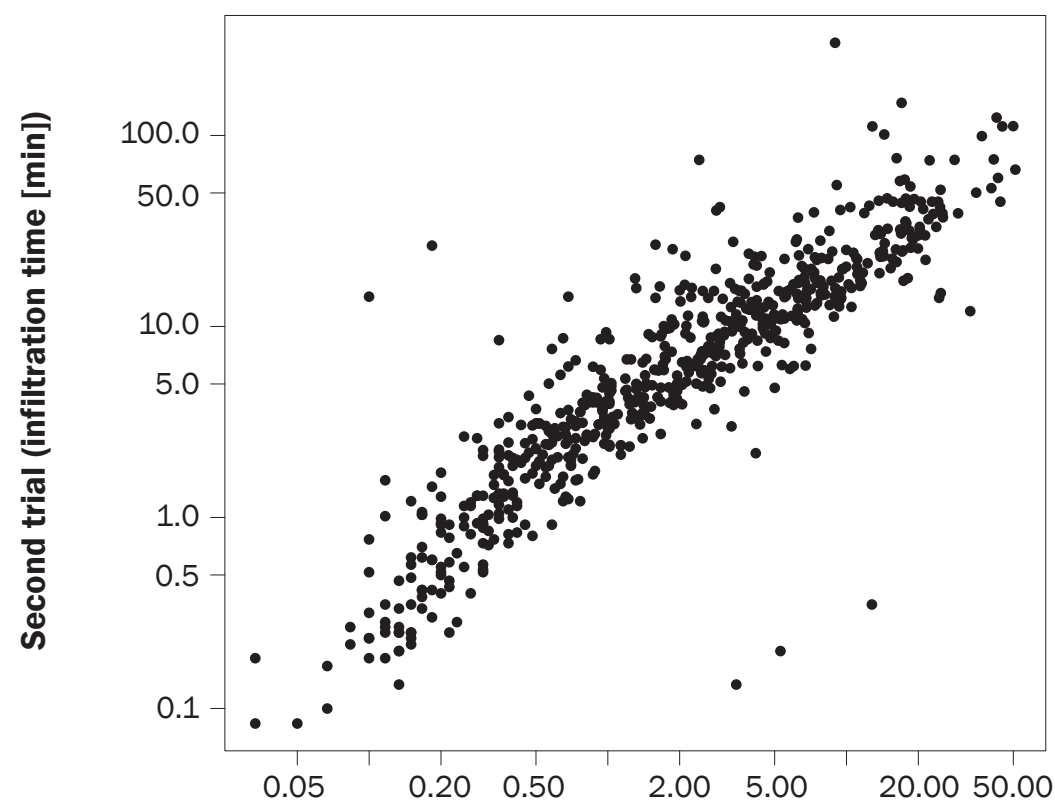

First trial (infiltration time [min])

and our results suggest they can also be useful coarse indicators of SOC and bulk density. Monitoring metrics should be selected specifically to address the goals and questions that motivate the data collection. Our study suggests that a simple single-ring water infiltration test can be a useful indicator of SOC and bulk density at a coarse resolution but is most likely not appropriate for questions requiring highly accurate and repeatable quantification of soil dynamic properties.

\section{Acknowledgements}

We are grateful to our team of biologists for conducting fieldwork and providing inspiring discussion on rangeland ecological function and measurement. We also thank landowners and managers for allowing access to study areas, the USDA Natural Resources Conservation Service for their support, and TomKat Ranch and the TomKat Ranch Educational Foundation for access, support, and vision. This manuscript was greatly improved by feedback from Kelly Garbach (senior ecologist, Point Blue Conservation Science, Petaluma, California), Luke Peterson (biologist, Point Blue Conservation Science, Vacaville, California), Mel Preston (biologist, Point Blue Conservation Science, Pescadero, California), and Chelsea Carey (senior ecologist, Point Blue Conservation Science, Petaluma, California). We would like to thank the S.D. Bechtel, Jr. Foundation, the TomKat Foundation, and the 11th Hour Project for financial support. This is Point Blue Contribution \#12512.

\section{References}

Burnham, K.P., and D.R. Anderson. 2003. Model Selection and Multimodel Inference: A Practical InformationTheoretic Approach. New York: Springer Science and Business Media.

Buttle, J.M., and D.A. House. 1997. Spatial variability of saturated hydraulic conductivity in shallow macroporous soils in a forested basin. Journal of Hydrology 1997:127-142.

\section{Figure 4}

Infiltration times $\left(450 \mathrm{~mL}\right.$ of water applied over $180 \mathrm{~cm}^{2}$ ) of the (a) five first and (b) second trials at each sampling location as a function of the mean at that location. Black points are the mean, and the gray vertical lines are the range of the minimum time to the maximum time at each point.

(a)

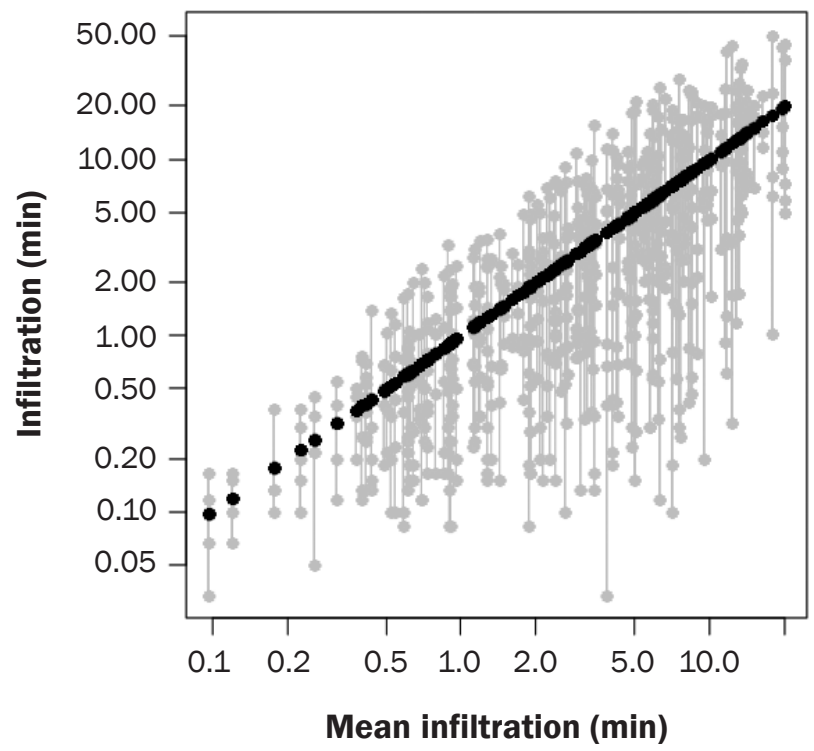

(b)

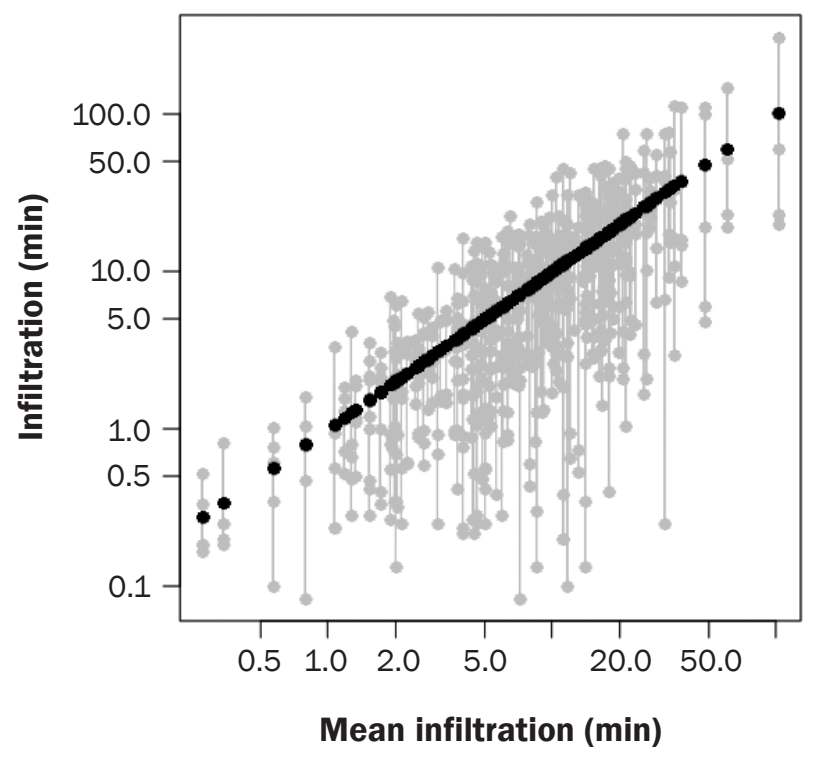




\section{Figure 5}

Pairwise correlation matrix of the first and second infiltration times, soil organic carbon (SOC), bulk density, water content, and texture. Asterisks denote significant correlations.

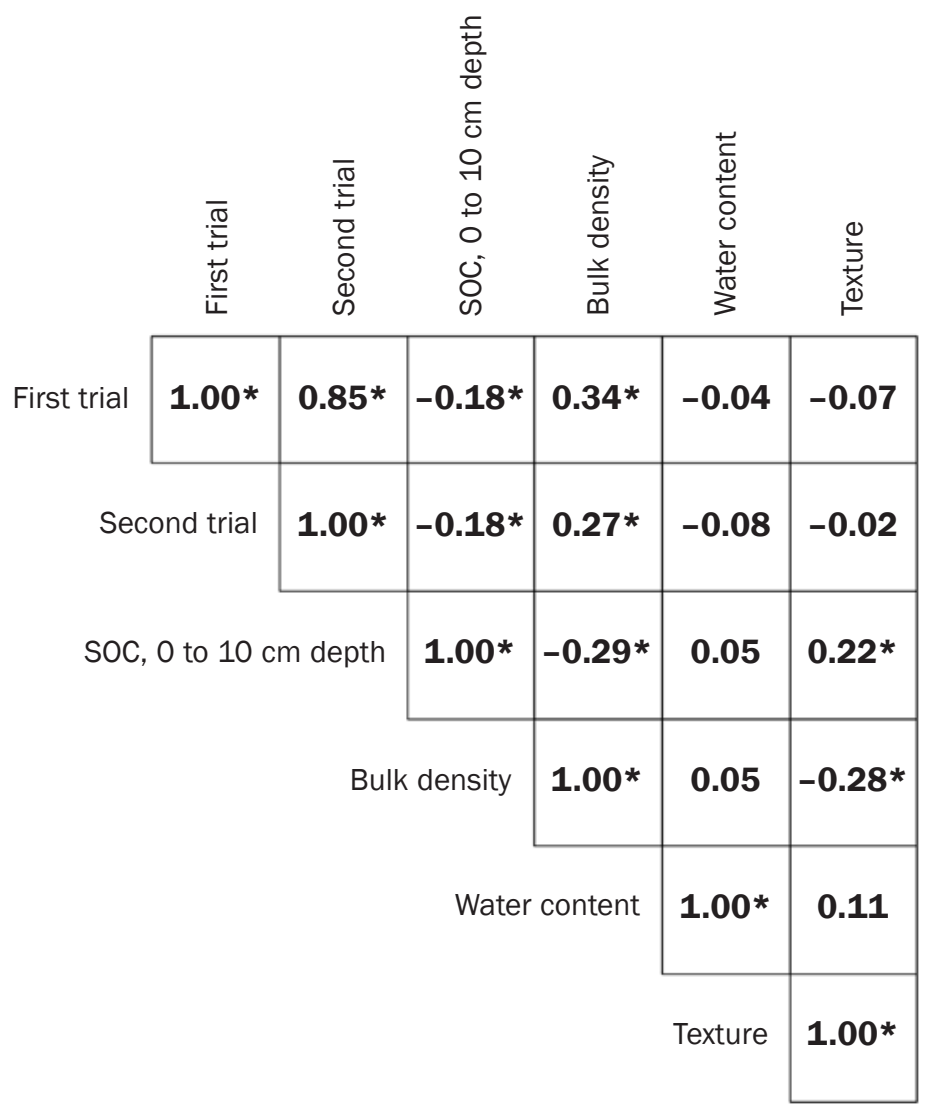

Franzluebbers, A.J. 2002. Water infiltration and soil structure related to organic matter and its stratification with depth. Soil and Tillage Research 66:197-205.

Grossman, R.B., and T.G. Reinsch. 2002. Bulk density and linear extensibility. In Methods of Soil Analysis, Part 4, eds. J.H. Dane and G.C. Topp, 201-228. Madison, WI: Soil Science Society of America.

Guissan, A., and W. Thuiller. 2005. Predicting species distribution: Offering more than simple habitat models. Ecology Letters 8:993-1009.

Hammond, A. 1995. Environmental indicators: A systematic approach to measuring and reporting on environmental policy performance in the context of sustainable development. Washington, DC: World Resources Institute.

Haverkamp, R., P.J. Ross, K.R.J. Smetten, and J.Y. Parlange. 1994. Three-dimensional analysis of infiltration from the disc infiltrometer 2. Physically based infiltration equation. Water Resources Research 30:2931-2935.

Heink, U., and I. Kowarik. 2010. What are indicators? On the definition of indicators in ecology and environmental planning. Ecological Indicators 10:584-593.

Huntington, T.G., C.E. Johnson, A.H. Johnson, T.G. Siccama, and D.F. Ryan. 1989. Carbon, organic matter, and bulk density relationships in a forested spodosol. Soil Science 148:380-386.
Jarrell, W.M., D.E. Armstrong, D.F. Grigal, E.F. Kelly, H.C. Monger, and D.A. Wedin. 1999. Soil Water and Temperature Status. In Standard Soil Methods for LongTerm Ecological Reseaerch, eds. G.P. Robertson, D.C. Coleman, C.S. Bledsoe, and P. Sollins. New York: Oxford University Press.

Jarvis, N.J., and I. Messing. 1995. Near-saturated hydraulic conductivity in soils of contrasting texture measured by tension infiltrometers. Soil Science Society of America Journal 59:27-34.

Kincaid, T.M., A.R. Olsen, D. Stevens, C. Platt, D. White, and R. Remington. 2013. spsurvey: Spatial survey design and analysis. $\mathrm{R}$ package version 3.3.3.

Lal, R. 1998. Soil Quality and Agricultural Sustainability. Chelsea, MI: Sleeping Bear Press, Inc.

Lowery, B., W.J. Hickey, M.A. Arshad, and R. Lal. 1996. Soil water parameters and soil quality. In Methods for Assessing Soil Quality, eds. J.W. Doran and A.J. Jones. Madison, WI: Soil Science Society of America.

Ludwig, J.A., D.J. Tongway, G.N. Bastin, and C.D. James. 2004. Monitoring ecological indicators of rangeland functional integrity and their relation to biodiversity at local to regional scales. Austral Ecology 29:108-120.

Niemeijer, D. 2002. Developing indicators for environmental policy: Data-driven and theory-driven approaches examined by example. Environmental Science \& Policy 5: 91-103.
Polley, H.W., D.D. Briske, J.A. Morgan, K. Wolter, D.W. Bailey, and J.R. Brown. 2013. Climate change and North American rangelands: Trends, projections, and implications. Rangeland Ecology and Management 66:493-511.

Porzig, E., N.E. Seavy, R.T. DiGaudio, C. Henneman, and T. Gardali. 2016. The Rangeland Monitoring Network Handbook V1.0. Petaluma, CA: Point Blue Conservation Science.

Pyke, D.A., J.E. Herrick, P. Shaver, and M. Pellant. 2002. Rangeland health attributes and indicators for qualitative assessment. Journal of Range Management 55:584-597.

R Core Team. 2016. R: A language and environment for statistical computing. Vienna: R Foundation for Statistical Computing. https://www.R-project.org.

Reynolds, W.D., B.T. Bowman, R.R. Brunke, C.F. Drury, and C.S. Tan. 2000. Comparison of tension infiltrometer, pressure infiltrometer, and soil core estimates of saturated hydraulic conductivity. Soil Science Society of America Journal 64:478-484.

Reynolds, W.D., and D.E. Elrick. 1985. In situ measurement of field-saturated hydraulic conductivity, sorptivity, and the $\alpha$-parameter using the Guelph permeameter. Soil Science 140:292-302.

Sakin, E. 2012. Organic carbon organic matter and bulk density relationships in arid-semi arid soils in Southeast Anatolia region. African Journal of Biotechnology 11:1373-1377

Sharma, M.L., G.A. Gander, and C.G. Hunt. 1980. Spatial variability of infiltration in a watershed. Journal of Hydrology 45:101-122.

Shaw, M.R., L. Pendleton, D.R. Cameron, B. Morris, D. Bachelet, K. Klausmeyer, J. MacKenzie, D.R. Conklin, G.N. Bratman, J. Lenihan, E. Haunreiter, C. Daly, and P.R. Roehrdanz. 2011. The impact of climate change on California's ecosystem services. Climate Change 109:465-484.

Stephens, D.B., K. Lambert, and D. Watson. 1987. Regression models for hydraulic conductivity and field test of the borehole permeameter. Water Resources Research 23:2207-2214.

USDA NRCS (Natural Resources Conservation Service). 1999. Soil Quality Test Kit Guide. Washington, DC: USDA Natural Resources Conservation Service. http:// www.nrcs.usda.gov/Internet/FSE_DOCUMENTS/ stelprdb1044790.pdf.

West, N.E. 2003. History of rangeland monitoring in the USA. Arid Land Research and Management 17:495-545

Wierda, A., and A.W.L. Veen. 1992. A rainfall simulator study of infiltration into arable soils. Agricultural Water Management 21:119-135.

Zuur, A.F., E.N. Ieno, N.J. Walker, A.A. Saveliev, and G.M. Smith. 2010. Mixed Effects Models and Extensions in Ecology with R. New York: Springer. 